strengths and weaknesses of each of these approaches in more detail.

1 Drummond MF, Davies L. Economic analysis alongside clinical trials. Int $f$ Technol Assess Health Care 1991;7:561-73.

2 Ludbrook A cost-effectiveness analysis of the treatment of chronic renal failure. Applied Economics 1981;13:337-50.
3 Sintonen $\mathrm{H}$, Alander V. Comparing the cost-effectiveness of drug regimens in the treatment of duodenal ulcers. Fourmal of Health Economics 1990;9:85-101. Hull RD, Hirsh J, Sackett DL, Stoddart GL. Cost-effectiveness of clinical diagnosis, venography and non-invasive testing in patients with symptomatic deep-vein thrombosis. N Engl f Med 1981;304:1561-7.

5 Teeling-Smith G, ed. Measuring health: a practical approach. Chichester: John Wiley, 1988 .

6 Thompson MS. Willingness to pay and accept risks to cure chronic disease. Am f Public Health 1986;76:392-6.

\title{
Taking babies' temperatures: science versus social taboos in battle over Baby Check
}

\author{
Stuart Handysides
}

Baby Check, a scoring system for assessing the severity of illness in babies under 6 months old, has not met with the success its developers expected. The inclusion of rectal temperature in the assessment was strongly opposed by the Royal College of Midwives, which refused to alter its view despite evidence of the safety and accuracy of rectal thermometry. British parents appear not to like rectal thermometers either. Most other medical bodies have supported Baby Check and the reason for midwives' opposition may have more to do with professional pique at not being consulted than clinical wisdom.

Babies have bad days when they cry, refuse to feed, and worry their parents and doctors. It is hard to tell whether the baby is seriously ill or just out of sorts and to know whether it should be cared for at home or in hospital. Baby Check is probably the best researched attempt to improve the discrimination of serious and trivial illness in infants, ${ }^{1}$ but it has also been the most controversial. Its launch in January 1991 was hijacked by an unexpectedly fierce attack from the Royal College of Midwives. The college refused to endorse

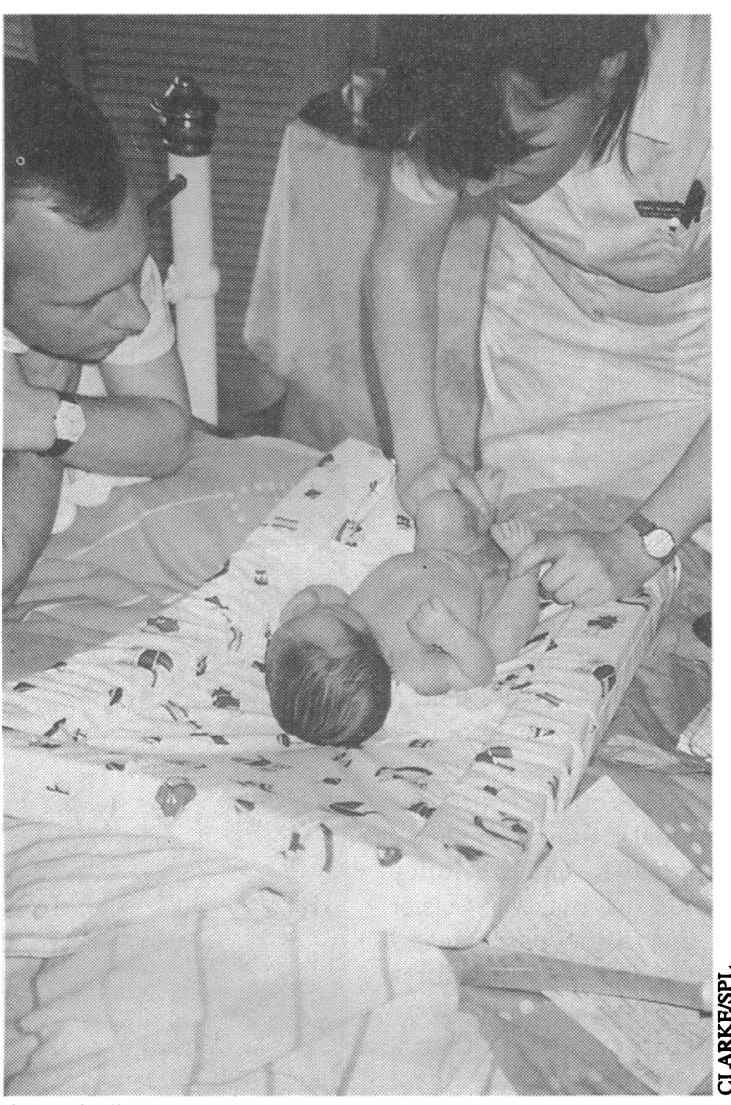

Seriously ill or just out of sorts? the project and issued a press release which said that Baby Check would make parents more anxious and that taking a rectal temperature (one of 19 observations in Baby Check) would cause rectal damage and allegations of sexual abuse. Potential sponsors for Baby Check evaporated, not wishing to be associated with a package that midwives said was dangerous. Was the college's attack justified or was there a hidden agenda? Was it attuned to public opinion, or did it express its own taboos and resistance to change? The story is one of conflict between science and sensitivity.

\section{The development of Baby Check}

Baby Check is a scoring system devised to help parents, doctors, midwives, and health visitors assess the severity of acute illness in infants under 6 months old. ${ }^{1}$ It was the result of four years of research by Dr Colin Morley and his colleagues in Cambridge and Melbourne, Australia, culminating in the publication of four consecutive papers in the Archives of Diseases in Childhood.1.4 Dr Morley said, "A House of Commons Select Committee report on post neonatal mortality found that mothers were slow to seek help, and that general practitioners do not appreciate the severity of a child's illness. ${ }^{\text {5 }}$ We realised this from our own experience and decided to set up a big study."

Morley and colleagues collected data on 1007 infants and used logistic and ordinal regression analyses to identify which symptoms and signs best distinguished well babies from seriously ill babies. Baby Check asks about seven symptoms over the past 24 hours including the nature of the baby's cry, fluid intake and output, vomiting, blood in the nappy, and drowsiness. The observer has to assess the baby's muscle tone, alertness, and breathing and whether there is pallor, cyanosis, or a rash; look for a hernia; and take the rectal temperature. Each symptom and observation is weighted, and the score increases with the severity of the baby's condition. Field trials of Baby Check were done with mothers at home, ${ }^{2}$ general practitioners, ${ }^{3}$ and hospital doctors. ${ }^{4}$ The Royal College of Midwives and other interested parties had received copies a month before the system was launched. Other professional bodies in Britain and abroad welcomed Baby Check.

\section{Professional responses}

The British Association for Accident and Emergency Medicine was very keen on the system, and asked to have the Baby Check score card for professionals in casualty departments. Parents who had used Baby Check and brought their children to hospital would then meet staff who were familiar with the system. Mr Stephen Miles, the association's honorary secretary said, "Baby Check is a potentially good triage system. It is a shame that it has not been taken up more widely." 


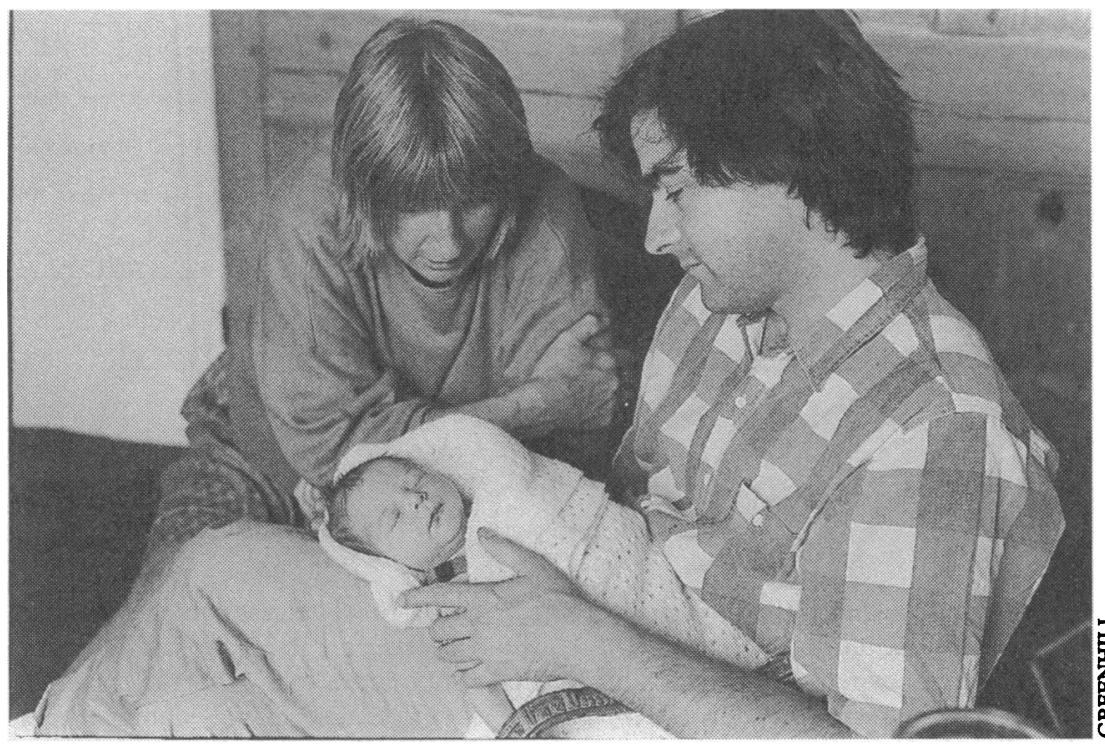

Sick or tired?
Check "on the grounds of the complexity of the documentation, and the implication of Baby Check's dominant advice to parents to use a rectal thermometer."

Morley's team did further research and published another paper which compared axillary and rectal thermometry in infants. ${ }^{8}$ It concluded that axillary measurement was too insensitive for accurate detection of an infant's high temperature. Reviewing earlier publications the team calculated that rectal perforation by a thermometer had occurred in less than one in two million measurements. In response, an editorial in the $B M \mathcal{F}$ concluded that British prejudice was the only real objection to rectal thermometers.' Joe Kai's survey of parents in north east England confirms the strength of this feeling ( $p$ 660). ${ }^{10}$

A revised version of Baby Check in easier language came out in April this year, along with a publication from the British Association for Accident and Emergency Medicine including all the same checks to be used in casualty departments. Morley's team had hoped that it would be distributed free to all first time parents. Although potential sponsors were put off by the reaction of the Royal College of Midwives, the team hopes that the cheaper new version will be purchased by health authorities to enclose in personal child health records. and offered constructive comments about the text, pointing out a "potential risk of parents trying to manage an illness or disease process on their own and only seeking appropriate medical or nursing assistance at the last possible moment." Miss Virginia Collis, the then president of the Association of British Paediatric Nurses said, "Baby Check can give parents the support they require to express their concern." She acknowledged that taking rectal temperatures was controversial but said, "the Baby Check thermometer is well marked and the directions for its use are clear. This coupled with the undoubted accuracy of the rectal route would seem to make the likelihood of injury associated with the practice low." The Health Visitors Association had reservations about its use without professional support and were concerned that it was a commercial product parents might feel obliged to buy.

The BMA and the Royal College of General Practitioners were enthusiastic but stressed that Baby Check should not take the place of maternal or clinical judgment. They wanted more field trials to be done, and the royal college offered to find general practitioners to help in the research. The BMA was concerned that the score card might increase the workload of general practitioners, despite the developers' belief that educating parents would reduce unnecessary night visits and emergency consultations. The Lancet suggested that it would reassure inexperienced mothers and keep babies who were slightly unwell or just grumpy out of doctors' surgeries. ${ }^{6}$

\section{Friendly persuasion}

Attempts to persuade the Royal College of Midwives of Baby Check's value were in vain. In response to the college's statements that axillary thermometry was adequate and preferable, the Child Growth Foundation, a charity promoting Baby Check, held a seminar in May 1991. Colin Morley was disappointed by the outcome: "The scientific evidence was presented for the accuracy of rectal temperatures but no consensus was reached because of an emotional reaction," he said.?

At a meeting in September 1991, Colin Morley said the text was being revised to make it easier to understand. He accepted that some parents and professionals preferred not to take rectal temperatures but maintained that axillary temperatures were inaccurate and that no temperature was better than a misleading one. Despite this olive branch the Royal College of Midwives Council still rejected Baby

\section{Why the controversy?}

The Child Growth Foundation is baffled by the Check. The system has been validated for use in the first six months of life whereas midwives' statutory responsibility to babies ends after 28 days and in practice they are involved only in the first 10 . In the succeeding months parents can feel anxious and an opportunity for parents to understand and look after their babies better.

The story is one of two professions locked in combat,

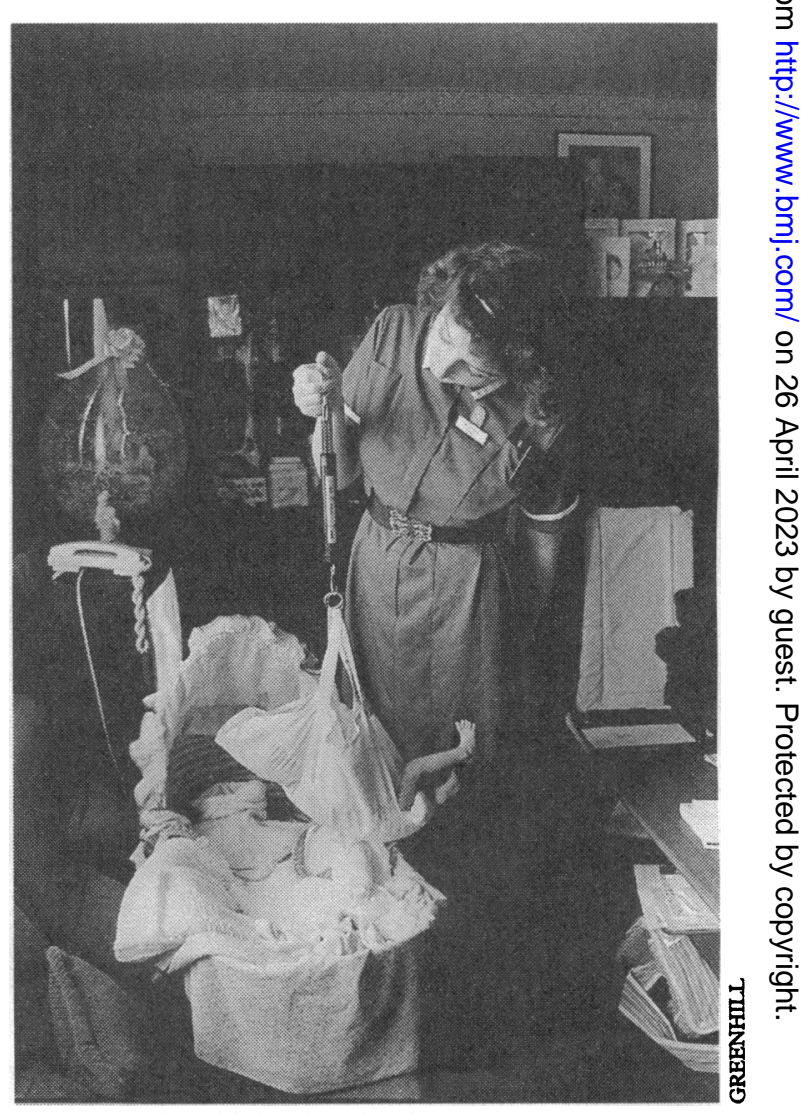

Midwives: jealous of their independence? response of the Royal College of Midwives to Baby unsupported, and the college has effectively blocked 
a "running battle" according to one Royal College of Midwives spokesperson. But perhaps measuring temperature is a smokescreen for the real issue. The first time the college was consulted about Baby Check was one month before its launch, when it was asked if it "might endorse it and midwives recommend it to their parent clients." There is a note of censure in a letter from Ruth Ashton, general secretary of the college, which says, "Many midwives have in the past seen superficial damage caused by taking babies' temperatures with rectal thermometers. Yet these professionals were not included in discussions suggesting that such a procedure could be recommended safely." Recommending a new product makes extra work and knowing their own and mothers' preferences, the college may have used the rectal thermometer as a convenient focus for rejection. Although three quarters of mothers in field trials found Baby Check useful, $40 \%$ did not like the thermometer. ${ }^{2}$

Midwives are jealous of their independence and will not be taken for granted. The college seems reluctant to discuss Baby Check beyond reiterating its initial press statement. If the college's views had been sought earlier perhaps Baby Check would have received a more favourable response. The college's attacking posture was politically adept, putting the onus on Morley to defend, but it was based on shaky ethical and scientific foundations.

1 Morley CJ, Thornton AJ, Fowler MA, Cole TJ, Hewson PH. Baby Check: a scoring system to grade the severity of acute systemic illness in babies under six months old. Arch Dis Child 1991;66:100-5.

2 Thomton AJ, Morley CJ, Green SJ, Cole TJ, Walker KA, Bonnett JM. Field trials of the Baby Check score card: mothers scoring their babies at home. trials of the Baby Check score chis Child 1991;66:106-10.

3 Morley CJ, Thornton AJ, Green SJ, Cole TJ. Field trials of the Baby Check score card in general practice. Arch Dis Child 1991;66:111-4.

4 Thornton AJ, Morley CJ, Cole TJ, Green SJ, Walker KA, Rennie JM. Field trials of the Baby Check score card in hospital. Arch Dis Child 1991;66: 115-20.

5 House of Commons Social Services Committee. First report. Perinatal, neonatal and infant mortality. London: HMSO, 1988.

6 Is the baby ill? Lancet 1991;337:485.

7 Smy J. Hackles rise on accuracy of test for infant fever. Doctor 1991 June 20:24.

8 Morley CJ, Hewson PH, Thornton AJ, Cole TJ. Axillary and rectal temperature measurements in infants. Arch Dis Child 1992;67:122-5.

9 Keeley D. Taking infants' temperatures. $B M{ }^{9}$ 1992;304:931-2.

$10 \mathrm{Kai} \mathrm{J}$. Parents' perceptions of taking babies' rectal temperature. $B M 9$ 1993;307:660-2

11 Ashton RM. "Baby Check." Midwives Chronicle 1991;104:109.

\section{OBITUARY}

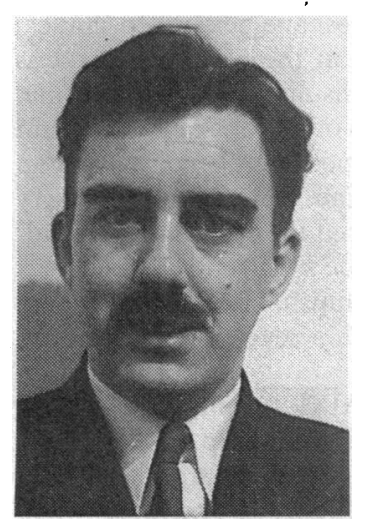

WB Wright

\section{W B WRIGHT}

FRCPSYCH

The first physician superintendent of Craig Phadrig Hospital in Inverness, Bill Wright spent the first 15 months of his appointment in commissioning the new hospital-which became the only hospital in the highlands for people with learning disabilities - and in visiting all potential patients in the highlands and islands. He acquired a unique knowledge of the geography of the area, its scattered population, and his patients and their family circumstances. Led by Bill, the management team made the hospital home to the patients from the day it opened and a highly respected institution in the highlands.

Bill retired in 1982 to Grantown on Spey, where he settled happily into the local community. Essentially a family man, he enjoyed walking with his wife in Strathspey, Switzerland, and Austria; he was also an accomplished skater and bridge player. $\mathrm{He}$ had an equable temperament and a quiet sense of humour, which he continued to display throughout his final lengthy illness. $\mathrm{He}$ is survived by his wife, Morag (Mollie), whom he married in 1953. He had two daughters.-ALEX R MORRISON

William Ballantine Wright, the physician superintendent of Craig Phadrig Hospital, Inverness, 1968-82, died 30 fune aged 67. Educated at Glasgow Academy and St Mungo's College, Glasgow (LMSSA 1950). Registrar at Little Plumstead Hospital, Norwich; area psychiatrist, Tidworth, Wiltshire; consultant and deputy physician superintendent at Royal Scottish National Institution, Larbert, Stirlingshire.

Obituaries must be submitted exclusively to the BMF; they should be under 250 words and submitted within three months of the person's death. We welcome self written obituaries and good quality photographs, and, as a medical journal, we encourage authors to include the cause of death.

\section{J A RICHARDSON \\ $\mathrm{MB}, \mathrm{CHB}$}

John Richardson practised in Fort William in what were arguably the halcyon days of the NHS: requests for calls on his weekly visit to the village of Ardgour were sometimes relayed by messages left under the windscreen wipers when his car was parked on the roadside. The long hours spent working and on call did not sap his energy for innovation, and he started the
Lochaber Medical Society in 1970; this flourishing local society remains unique in the highlands,

Outside work John's interests were wide. He was a member of the Saltire Society, the Rotary, curling and mountaineering clubs, and the Mountain Bothies Association. He was also treasurer and secretary of the local Scout Association. His awareness of the plight of the homeless (before the advent of any supportive legislation) encouraged him and his wife, Sylvia, to start a local branch of the charity Shelter; fund raising led to the purchase of several caravans, which were made available locally for homeless people.

Sadly, in 1979 John's illness-Huntington's chorea -became apparent and he had to retire from medical practice; always an optimist, he was soon looking for other work and was for a time employed as a gardener. He took up skiing and tried fishing. Latterly he gained-and gave-much encouragement from his attendance at an adult training centre. For the last four years he required continuous nursing care. John is survived by Sylvia, whom he met at university, and by their three daughters, Jill, Carol, and Sara.-CHRIs ROBINSON

fohn Archibald Richardson, a general practitioner in For William, Inverness-shire, 1968-79, died 17 fuly aged 49. Borm Argyllshire, 1943; studied medicine at Glasgow University (MB, ChB 1967). Also part time anaesthetist at Belford Hospital, Fort William.

\section{P SULLIVAN} $\mathrm{MB}, \mathrm{CHB}$

Peter Sullivan was senior partner in his practice in Oldham for 33 years before he retired aged 70 . His unassuming manner hid a keen diagnostic acumen. His work was underpinned by a devout Christian faith, and for more than 10 years he was a volunteer doctor for the Across Trust, accompanying nine groups of seriously ill and disabled people in a Jumbulance to Lourdes, the French Alps, and Switzerland.

Outside medicine Peter's interests were varied since he was a great believer in keeping active, both mentally and physically. He loved the sea; took evening classes 